\title{
Learning by Playing via Survey Platforms to Comprehend Environmental Management
}

\author{
José S. Torrecilla \\ Complutense University of Madrid
}

In this work, a technique based on the learning by playing method has been tested in a regulated class that is taught at the Spanish Complutense University of Madrid (Environmental Management). This application was done during the academic two courses 2017-18 and 2018-19. The applicability of this technique has been checked in two pilot groups with 56 students (25 and 31 students, respectively). Given the game like features of this learning approach, it helps students improve their comprehension and overall performance in the class. On the other hand, it is presumable that the student can recall the acquired concepts for more time. The professor is able to control the transmission of the concepts easily and the relation with the students is closer. Therefore, it helps decrease the nonattendance and dropout rates. Finally, it strongly enhances the development of the innovation capabilities of the students.

Keywords: environmental education, learning by playing, learning process, Kahoot!, Google forms

\section{INTRODUCTION}

Playing during any type of learning process is useful for students. It gives many advantages not only for the children but also for undergraduate and graduate students, regardless of age. These advantages are related with the adequate development of cognitive parts of the brain (Heo et al., 2018; Tobar and Lencina, 2017). This is the reason why playing or learning through games should be a driving force in many learning processes. It is well-known that most people enjoy playing and even, in some cases, they become hooked to the game, which in this context becomes linked with acquiring and understanding new concepts. And then, technical and complicated ideas are easier to comprehend by playing than hearing the professor's lectures or learning from a text book alone.

Currently, it is known that there are many types of games that help improve a great diversity of people's skills and activate different regions of their brains (Andreu-Andres and Garcia-Casas, 2011; Parong and Mayer, 2020). It gives many advantages concerning the students' training, among other things: (i) by playing, different aspects such as excitement, rewards, competitiveness, or challenges become a part of learning. All of these are intrinsic qualities of learning new concepts and ideas, as the learning desire becomes a powerful motivator; (ii) winning is not the most important part in most of games. The students start to play any game as something new, without any fear of failure. This trait of learning by playing shows the path to teach about innovation skills that will be very important in their future professional careers; (iii) biochemically speaking, learning by playing leads to the generation of endorphins that facilitate increasing the student's creativity and learning capability; (iv) without any doubt, friendly relationships are created by 
playing games and the knowledge is easily shared (Rodriguez-Fernandez, 2017). These characteristics are very relevant in the higher education environment (Bicen and Kocakoyun, 2018; Parong and Mayer, 2020).

Gamification and its procedure directs learning focused on the student. Therefore, it matches perfectly with the new educational system that is being implanted in most of the universities around the world. In the Spanish University, the traditional learning methods have been changed since its incorporation to the European Higher Education Area.

The main objective of this work is focused on evaluating the applicability of playing games in the environmental management training. Two different software will be implemented in this regard: a wellestablished e-learning software such as Kahoot! and other new application developed by Google known as Google Forms. In this line, two software will be employed during a course named "Environmental Management".

\section{MATERIALS AND METHODS}

In this section, the learning by playing technique and every required equipment and software to carry out their adequate performance is explained in detail.

\section{Main Characteristics of the Students and Subject}

The learning by playing method was implemented in a pilot group of two environmental management courses (vide supra) composed of 25 (14 women and 11 men) and 31 (17 women and 14 men) students during the academic two courses 2017-18 and 2018-19, respectively. Their mean age is about 32 years old. The students come from different Spanish-speaking countries, and have different backgrounds (engineers, architects, chemists, environmental lawyers, etc.)

The learning by playing methodology ('learn, play, teach'; LPT) has been applied in the two editions of the courses named Environmental Management (EM) courses that covers a full a month (July 2018 and July 2019; 75 hours each). Every class is 60 minutes long. These form part of the Spanish Complutense University of Madrid's courses in its non-formal education block. This course has successfully been taught during the last eight years. In every edition, the course is technically and administratively evaluated by the students of the university.

\section{Learning by Playing Technique}

The LPT approach is an innovative bi-directional method that simultaneously helps the student in his/her learning and gives information to the professor about the level of the general comprehension level. While the student is playing, the results are stored for real-time analysis regarding how well the concepts that are explained are being understood by the students (Wulf et al., 2018).

The equipment used to implement the LPT method is based on four different parts: (i) A questionanswer (Q\&A) database for every class; (ii) implementation of this test using software; (iii) Wi-Fi for internet connection (IC); (iv) a Data Treatment Center (DTC). The test has been done using two free software: Kahoot! (free version) and Google Forms.

The course topics consist of 12 lessons. The Q\&A lists are prepared by the professor, and they consist of a group of 720 multiple choice questions (60 Q\&A x 12 lessons). Every lesson (60 questions) is composed of 12 blocks, and each block is composed of five Q\&As (12 blocks x 5 questions). In every block, each Q\&A is selected randomly to not be repeated in any case. The transmission of the information between students and professor was done via internet. Although internet service will be used here, other transmission systems way such as Bluetooth could be alternatively used (Versichele et al., 2014).

To transmit the information, a computer, laptop, tablet, or even a simple smartphone with the capability of transmitting information through internet could be used. Depending on the software, the IC is just used by the user to read and/or answer the questions on-line. This information and its owner is sent to the central signal receptor to treat it. Its role is just to receive the information and send it to the DTC, which is simple software that receives all information from the LPT and calculates the main statistical results of the 
multiple-choice questions answered by the student. These results are graphically represented and sent at real-time to the professor and/or students.

\section{Software Used}

To implement this teaching methodology, two free software were independently used: Kahoot! and Google Forms. These are described below:

- Kahoot! is a free game-based learning platform (https://kahoot.com) widely used as a dynamic tool for educational purposes or different fields (Bicen and Kocakoyun, 2018). This software is available as a mobile application (iOS or android systems) or in a browser. Kahoot! software is a well-known free gamification tool (Rodriguez-Fernandez, 2017). It has been used here because is very straightforward and generalizable to other completely different knowledge fields. The only disadvantage is based on the necessity to use an IC (Saleh and Battisha, 2020).

- Google Forms is a personalized survey or quiz (https://docs.google.com/forms). This free tool allows collecting information from users. Once the information is collected, it is automatically connected to a database (spreadsheet). It is provided with the survey and quiz responses. Although this software has not been designed for these types of applications, its characteristics make it suitable in this high educational field. Google software is present in nearly all new computers, smartphones, tablets, and so on, by default, which easily enables is implementation in this learning field with little changes regarding formats (Saleh and Battisha, 2020).

\section{Details of the Learning Procedure}

The LPT method has been implemented in two pilot program in the aforementioned courses. The classroom where it was done is a computer room (49 computers) with adequate IC (vide supra). The communication between students and professor is based on Wi-Fi, and the information is properly exchanged between emissors and receptor (vide supra). There are three main benefits during this teaching process, Figure 1:

(1) This methodology is applied so the professor can monitor in real-time the rate that the concepts are being understood by the students. This will be known as the professor monitoring (PM) phase.

(2) This methodology is used by the students to control their own learning process (student monitoring phase; SM).

(3) And finally, and from a global point of view, this methodology is based on a dynamic game which facilitates the comprehension of concepts.

The two first points are developed in a different way. Once the test is shared with the students, on one hand, the professor receives in his computer the main statistical results at the same time as he is teaching the concepts, and he can take an informed decision regarding the progress of the class and the next topics. On the other hand, the students can answer individually or in groups. In this way, the student can know in what extension the concepts have been taken during the class. 
FIGURE 1

\section{SCHEME OF LEARNING BY PLAYING METHODOLOGY (SP: STUDENT MONITORY PHASE; PM: PROFESSOR MONITORING)}

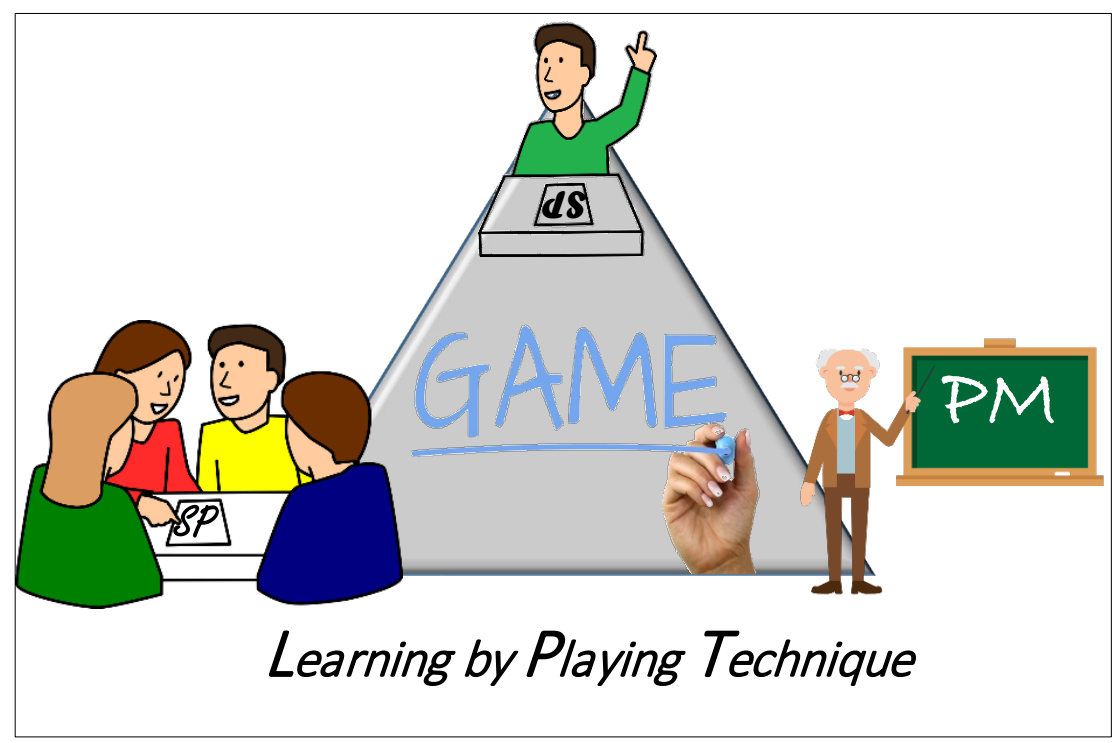

To carry out the PM, both mentioned software (Kahoot! and Google Forms) have been applied. In this case, all the information needed to play and to answer the test is given in the teachers' slides. On the other hand, to carry out the SM, the screen of the professor's computer is shown on all the student's devices. Once finished answering, the solution of the questions is instantly published and a scoring system operates providing instant results. This way, a ranking is set showing who performed the best (response time and correct answer), adding competitiveness into the teaching process, which also boosts the willingness to learn.

Once the test ends, and all the students have provided their answers, lists with all scores and results of every student are automatically generated in both software (Kahoot! and Google Forms). This represents relevant information concerning the level of understanding during the students' training as well as serve as a partial alternative to the evaluation using exams.

\section{RESULTS AND DISCUSSION}

The environmental management course is taught in the Spanish Complutense University of Madrid (vide supra), and it covers a summary of the most important parts of this topic including basic concepts of environment, waste management, analysis of environmental impacts, environmental models, and so on. In relation to the 56 students, they have very different backgrounds including lawyers, architects, as well as environmental scientists, among others. Because of this, it is important to determine when the students understand the most important concepts and when they do not, and relate the results to their backgrounds.

\section{LPT Validation by Kahoot! and Google Forms Software}

Regarding Kahoot! during the PM part, once the professor has the permission of the students and the devices are ready, the students open the application or open the URL (https://kahoot.it/). Then, the professor starts to explain the concepts, and after some time, the dynamic tests start.

The students then write the "game PIN" in Kahoot! to enter the multiple choice question page (vide supra). During this time, the professor is teaching and speaking about the concepts as well as revising the evolution of the tests. Once a group of questions have been finished, the professor has valuable information about how a given concept has been understood by the class. In this moment, the professor has to decide 
whether to continue with the program or further explain the previous content of the test, depending on the results.

Regarding the SM phase, the procedure is different. Once the class is close to ending (about 10 minutes earlier), the professor opens the application on the screen for the whole class to see. This way, the "game PIN" is presented to the students. Once, the students input it, Kahoot! starts the game. These games could be done in two ways, individually and in groups. Here, the students' preferences are also tested (see below). The answers can be sent using a smartphone, laptop, tablet, or a computer. The students can use the equipment that is best for them.

After every question, the solution is discussed by the professor and students. And at the end of a group of questions, the system reveals the winner/s or a winning team/s. This procedure is repeated along the classes and all scores of everyone or every team are recorded. In all cases, every score is taken into account during the final evaluation of the students. This represents a reward for participating in the game as well as promoting teamwork and encouraging a dynamic learning atmosphere. These are very positive transversal characteristics that the game gives in the technical development of every student.

On the other hand, although the Google Forms application has not been designed for these type of games, it can be easily adapted to share multiple choice questions with the students. The advantage is the simplicity of downloading Google applications on a computer, laptop or smartphone. PM and SM applications have been tested with this software. Using Google Forms, the validation procedure is totally different to the followed when using Kahoot! In this case, the professor has to send invitations to every student and he has to inform them when each multiple choice question block has to be answered. This information is given during the class. Once the blocks of questions have been answered, their results are automatically sent to the professor. Using this information, the professor decides when to go ahead with new concepts. This multiple choice questions can also be done individually and in groups, but the scores are not sent directly to the professor, who has to select the winner/s according to the scores.

\section{LPT Opinion Survey Results}

To evaluate the satisfaction rate of the students with this methodology, a survey was done. This study was carried out at the end of the two courses. The survey consists of 12 questions, eight of them multiple choice and the others are open questions. The first question is focused on the selection of the most suitable software. The scores were evaluated from 0 (negative) to 10 (excellent). The average scores for Kahoot! and Google Forms were similar (8.7 and 7.9, respectively). In regard to answering the questions individually or in teams, the scores were also similar ( 9.3 and 8.3, respectively). Given that the results are very close, both software could be suitable to carry out this type of game, Figure 2. Nevertheless, Kahoot! software and answering individually were slightly favored by the students of this course.

FIGURE 2

\section{SURVEY RESULTS REGARDING SOFTWARE AND ANSWERING METHOD}

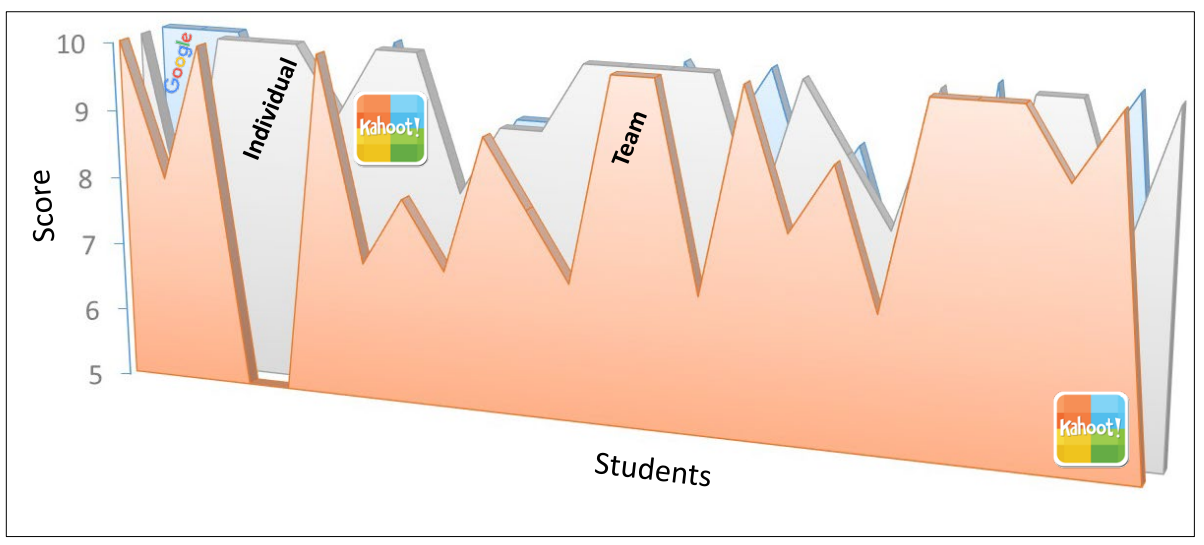


As it was mentioned, the preferred device to answer the questions has been evaluated. Every student tested computers, smartphones, laptops, and tablets. Finally, the students preferred answering the multiplechoice questions using a computer, laptop, or smartphone, but not tablets. In the opinion of the students, tablets are not adequate to answer the questions rapidly.

Regarding satisfaction with the training methodology and its ability to facilitate the comprehension of environmental management concepts, two multiple choice questions were asked in the survey. Four options were given $(0-25 \%, 25-50 \%, 50-75 \%$, and 75-100 \%) in both questions. Regarding the satisfaction with the methodology, $80 \%$ of students (45 out of 56 students) were very satisfied (75-100\%) with this methodology, Figure 3. On the other hand, $80 \%$ consider that this methodology helps learn new concepts easier than more typical teaching approaches (75-100\%).

\section{FIGURE 3 \\ STUDENTS' SURVEY ANSWERS REGARDING LOWER DIFFICULTY AND SATISFACTION, 56 STUDENTS PROVIDED FEEDBACK (100\% OF THE CLASS)}

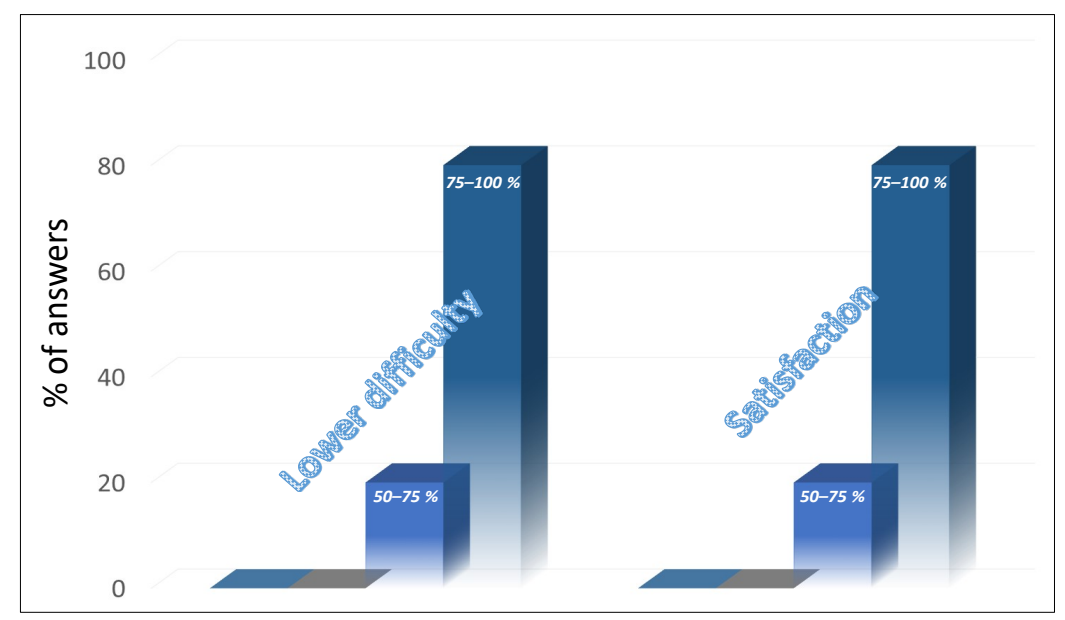

Another question in the survey referred to the influence of this methodology on the student-professor relationship. It is known that in every game, a relationship is established between players and it commonly results in an increase in confidence between them. In this case, 55 out of the 56 students considered that this game results in an improvement in this sense. Undoubtedly, this enhancement let them get to know each other better, and so, the professor can directly help the students, who willingly seek and cherish advice.

In parallel, it is very important to know if the student would like to apply the methodology in their professional life. Focusing on the high education field, 45 of the students $(80 \%)$ would apply this methodology in academic tasks. Regarding other technical areas, $96 \%$ of students stated that they would consider applying this methodology in their professional lives (Consulting service, lawyer's office, and so on). Therefore, the same technique could be applied to transversal themes.

On the other hand, currently there are many proposals to fight against the poor class attendance, but nearly all are based on threatening the student with reducing their final scores if they do not attend regularly to class. Here, a measure to fight against this problem is presented, as the tool is based on attracting the student by having a good time while learning environmental concepts. In this line, the student is asked about the influence of this methodology on the attendance to class, and $80 \%$ feel that this methodology is a good tool to increase class attendance.

As the last question, the students were asked for three adjectives that describe the methodology. And in most of the cases the words "dynamic", "innovative", "interactive", and "fun" were stated, Figure 4. The global evaluation of the LPT methodology applied was positive, as 55 out of 56 students (98\%) think that this methodology is better than the other classical ones. This fact has encouraged to extend this methodology to other classes in other programs from our university. 


\section{FIGURE 4}

\section{PYRAMID-LIKE DIAGRAM SHOWING THE ADJECTIVES USED BY THE STUDENTS TO DESCRIBE THE LPT METHODOLOGY (BIGGER WORDS ARE THE MOST USED ADJECTIVES; FROM BOTTOM TO TOP)}

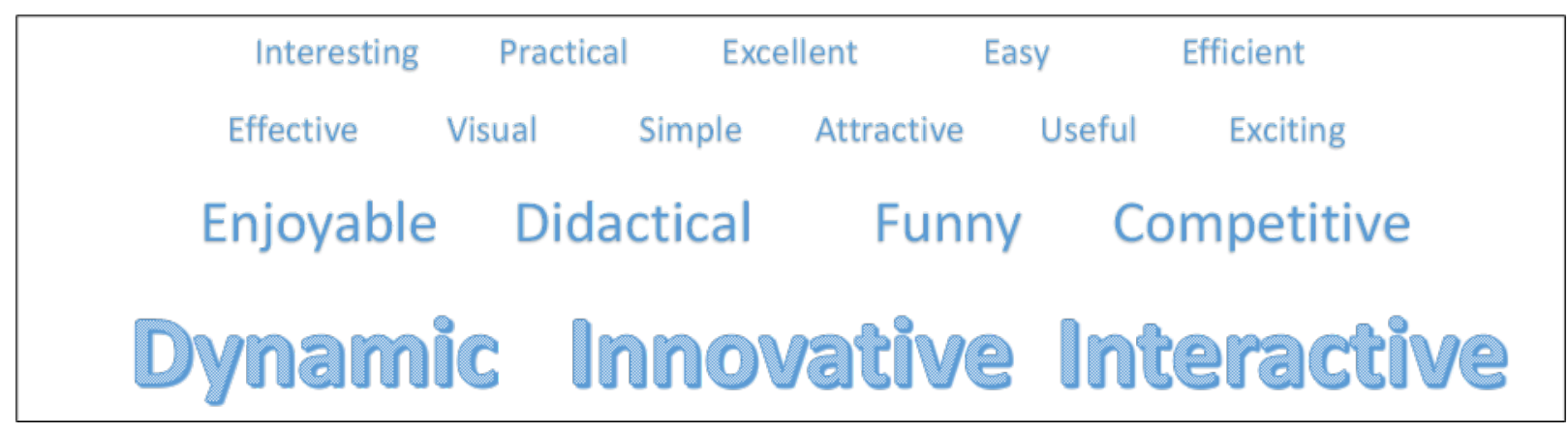

The global valuation of the LPT methodology applied, 54 out of 56 students (96\%) thinks that this methodology is better than the other classical ones used before in their home countries in. This evaluation encourage to extend this methodology to other subjects in other programs from the University.

\section{ACKNOWLEDGEMENT}

This work has been carried out with the financial support of the SL UCM 2019/21_14 project and the Madrid City Council.

\section{REFERENCES}

Andreu-Andres, M.A., \& Garcia-Casas, M. (2011). Perceptions of Gaming as Experiential Learning by Engineering Students. International Journal of Engineering Education, 27, 795-804.

Bicen, H., \& Kocakoyun, S. (2018). Perceptions of Students for Gamification Approach: Kahoot as a Case Study. International Journal of Emerging Technologies in Learning, 13, 72-93.

Heo, J., Ryu, J., Yang, H., Kim, A.C.H., \& Rhee, Y. (2018). Importance of playing pickleball for older adults' subjective well-being: A serious leisure perspective. Journal of Positive Psychology, 13, $67-77$.

Parong, J., \& Mayer, R.E. (2020). Cognitive consequences of playing-training games in immersive virtual reality. Applied Cognitive Psychology, 34, 29-38.

Rodriguez-Fernandez, L. (2017). Smartphones and learning: Use of Kahoot in the university classroom. Revista Mediterranea Comunicacion-Journal of Communication, 8, 181-189.

Saleh, M., \& Battisha, M.A. (2020) Proposed Paradigm for the Requirements for Designing and Using Digital Games-Based Learning by Educable Intellectual Disabled Children. Technium Social Sciences Journal, 2, 36-66.

Tobar, F.L., \& Lencina, M.J. (2017) The "Learning through play" project. Importance of interdisciplinary work among children born prematurely and their family groups in an area of high socioenvironmental risk. Archivos Argentinos de Pediatría, 115, 588-594.

Versichele, M., de Groote, L., Bouuaert, M.C., Neutens, T., Moerman, I., \& Van de Weghe, N. (2014). Pattern mining in tourist attraction visits through association rule learning on Bluetooth tracking data: A case study of Ghent, Belgium. Tourism Management, 44, 67-81.

Wulf, G., Lewthwaite, R., Cardozo, P., \& Chiviacowsky, S. (2018). Triple play: Additive contributions of enhanced expectancies, autonomy support, and external attentional focus to motor learning. Quarterly Journal of Experimental Psychology, 71, 824-831. 